\title{
Clinical and epidemiological study of leprosy cases in the University Hospital of Brasília: 20 years - 1985 to 2005
}

\author{
Estudo clínico-epidemiológico dos casos de hanseníase do Hospital Universitário \\ de Brasília: 20 anos - 1985 a 2005
}

\author{
Gerson Oliveira Penna ${ }^{1}$, Ana Maria Pinheiro ${ }^{2}$, Lucas Souza Carmo Nogueira ${ }^{3}$, \\ Luciana Rabelo de Carvalho ${ }^{4}$, Marcela Bahia Barretto de Oliveira ${ }^{4}$ \\ and Verena Portela Carreiro ${ }^{4}$
}

\begin{abstract}
Hansen's disease, also known as leprosy, is an infectious disease still prevalent in Brazil. It is a chronic illness with acute immunological phenomena known as leprosy reactions. In the Federal District of Brazil, the University Hospital of Brasília is the reference centre for leprosy care. The study aimed to characterize the clinical and epidemiological profile of Hansen's disease patients at the University Hospital of Brasilia, by descriptive, retrospective analysis of 1,124 patients over the period from 1985 to 2005. The pattern of leprosy in this study demonstrated that type 2 leprosy reactions were common, especially in the lepromatous form and presented a direct correlation with the bacilloscopic index. The prevalence and frequency of severe complications, such as leprosy reactions, emphasize the importance of the ongoing study of leprosy and the need for continual improvement in the scope of knowledge concerning its treatment.
\end{abstract}

Key-words: Hansen's disease. Leprosy. Epidemiology. Leprosy reaction. Histopathology.

\section{RESUMO}

Hanseníase, também conhecida como lepra, é doença infecciosa prevalente no Brasil. Caracteriza-se por curso crônico, com fenômenos imunológicos agudos denominados episódios reacionais. No Distrito Federal, o Hospital Universitário de Brasília é referência na assistência da hanseníase. 0 objetivo do estudo foi caracterizar o perfil clínico-epidemiológico dos doentes portadores de hanseníase do Hospital Universitário de Brasília. Foi realizada análise descritiva e retrospectiva de 1124 doentes portadores de hanseníase no período de 1985 a 2005. 0 padrão da hanseníase no nosso estudo concretizou-se por apresentar maior prevalência de reações do tipo 2, especialmente na forma lepromatosa e correlacionando-se diretamente com o índice baciloscópico. A significativa prevalência e frequiência de complicações graves como os episódios reacionais ressaltam a importância do estudo da doença e a necessidade de aprimoramento contínuo dos conhecimentos sobre a mesma.

Palavras-chaves: Hanseníase. Lepra. Epidemiologia. Reação hansênica. Histopatologia.

Leprosy, Hansen's disease (HD), is a granulomatous, chronic disease caused by Mycobacterium leprae, which mainly affects the skin and peripheral nerves ${ }^{3031}$.

In 2006, the World Health Organization (WHO) was notified of 219,826 new cases of the disease worldwide ${ }^{32}$. Brazil, India, Madagascar, Myanmar, Nepal, Tanzania and Mozambique are the countries with the highest prevalence of $\mathrm{HD}^{13293031}$. Brazil is responsible for $80 \%$ of all $\mathrm{HD}$ notifications in Latin America and is the second most endemic area in the world, after India 9 .

The strain of Mycobacterium leprae responsible for the disease in the majority of the Americas is closest to the European/
North African variety, which indicates that colonialism and emigration from the old World quite likely contributed to the introduction of Hansen's disease to the New World ${ }^{18}$.

The prevalence rate in Brazil in 1985 was 16.4 cases per 10,000 residents $^{20}$, dropping to $1.5 / 10,000$ in $2005^{14}$, a decline that was strongly influenced by operational factors, such as the treatment period. However, the prevalence rate is not the most adequate epidemiological indicator to monitor an endemic disease $^{28}$. Despite the fact that the prevalence rate has subsided during recent years, an increase in the coefficient of Hansen's disease detection has been observed ${ }^{27}$. This demonstrates that,

\footnotetext{
1. Tropical Medicine, Tropical Medicine Department, Medical School, University of Brasília, Brasília, DF. 2. Dermatology Department, Medical School, University of Brasília, Brasília, DF. 3. Dermatology Department, Medical School, University of Brasília, Brasília, DF 4. Medical Students, University of Brasília, University Hospital of Brasília, Brasília, DF. Address to: Dr. Gerson 0. Penna. SQN 112 Bloco J/Apt ${ }^{\circ}$ 307, 70762-100 Brasília, DF.

Tel: $55613274-4941$

e-mail: gpenna@terra.com.br

Recebido para publicação em 02/07/2008

Aceito em 25/11/2008
} 
on one hand, the introduction of multi-drug therapy (MDT) has brought with it the possibility for curing these patients, but on the other, it has not had the expected impact of diminishing the sources of infection. The mortality rate in relation to leprosy is similar to that of the general population ${ }^{22}$.

It is important to note that the official position of the Brazilian Dermatological Society has been to disagree with the changes undertaken in global and national Hansen's disease policies in pursuit of the elimination of leprosy ${ }^{28}$.

The distribution of the disease is not homogeneous in Brazil ${ }^{27}$. The new case detection rate in the northern region was 5.6 cases per 10,000 population in 2005, whereas southern Brazil registered a rate of only $0.7 / 10,000^{14}$. The majority of cases are located in cities and the disease is considered endemic to urban areas ${ }^{27}$.

There is no evidence that racial factorsinfluence the disease ${ }^{24}$ or that gender is associated with susceptibility. It is more frequent among those over 15 years of age, thereby mostly affecting those in the working age population ${ }^{2}$.

The important diversity of clinical, pathological and microbiological findings related to leprosy is a result of the variable levels of cellular immunity to Mycobacterium leprae among the patients affected by $\mathrm{it}^{25}$. It varies from a paucibacillary disease, in which few bacilli are present, to a multibacillary disease, where a significant bacillary load is present in lesions spread throughout the body surface ${ }^{5}$.

According to Ridley and Jopling (1966), clinical and histopathological findings led to the classification of leprosy in the following forms: tuberculoid (TT), borderline tuberculoid (BT), borderline borderline (BB), borderline lepromatous (BL) and lepromatous $(\mathrm{LL})^{23}$. In some cases, clinical presentation of an indeterminate form (I) occurs ${ }^{24}$. This system made it possible for researchers around the world to classify patients in a standardized way.

The tuberculoid end of the spectrum is the result of an intense cellular immune response, with the predominance of Th1 lymphocytes, while the lepromatous end is characterized by limited cellular immunity and the presence of $\mathrm{Th} 2^{29} 3031$.

Transmission occurs primarily from person to person ${ }^{9}$. In addition to individual immunological conditions, other factors that influence the risk of developing the disease include the local levels of endemicity and unfavorable socioeconomic conditions ${ }^{1320}$, particularly where several individuals must share the same room. The risk is even greater if the index case in the family presents the lepromatous form of the disease, or conversely, it is lower if the primary case is tuberculoid ${ }^{9}$, which is obviously affected by the level of susceptibility of the household contacts. However, it is difficult to identify the individual and the environmental risk factors, given that the disease presents a long incubation period that varies on average from 2 to 5 years for tuberculoid cases and 8 to 12 years for lepromatous cases ${ }^{10}$. Recent studies show strong evidence that susceptibility to this disease is also controlled by genetic factors, more specifically in a locus detected on the 6q25 chromosome ${ }^{1617}$, where an allele linked with low lymphotoxin- $\alpha$ production is the greatest risk factor ${ }^{1}$.
Initially, patients usually present with skin lesions and altered thermal sensitivity, potentially progressing to altered sensitivity to pain and touch, or muscle wasting as a result of the effect of the disease on the peripheral nervous system (weakness in the limbs) and, in rare cases in the advanced stages, painless burns or ulcers of an anesthetic hand or foot ${ }^{30}$. The tuberculoid end of the spectrum is characterized by the presence of a single or few lesions and these are maculae or plaques with clearly-defined borders; at the lepromatous end, the lesions tend to be multiple maculae distributed throughout the skin surface ${ }^{31}$. Mycobacterium leprae has a particular tropism for peripheral nerves, causing alterations in thermal, pain and tactile sensitivity, affected in that order ${ }^{24}$.

The diagnosis of leprosy is essentially clinical and epidemiological in nature ${ }^{31}$ and is based principally on the existence of skin lesions, reduced sensitivity and nerve thickening ${ }^{4}$, but it can also be corroborated by means of bacteriological and histopathological analysis ${ }^{11}$.

Leprosy reactions are acute inflammatory events that occur over the chronic course of the disease and can affect skin and nerves due to the tropism of Mycobacterium leprae for Schwann cells and macrophages $^{21}$. There are two types of reactions: type 1 reactions occur mostly in patients with some degree of cellular immunity, such as tuberculoid and borderline cases (Th1-type response); type 2 reactions are mediated by antibodies, but the formation and concentration of immunocomplexes with the subsequent system activation have an important role, occurring mostly in lepromatous and in some borderline cases (Th2-type response) ${ }^{419}$, and the most common clinical manifestation is erythema nodosum leprosum $(\mathrm{ENL})^{34}$. Approximately $30 \%$ of multibacillary patients (lepromatous and borderline forms) experience some reaction episode during the course of the disease ${ }^{13}$.

Type 1 reaction is characterized by acute inflammation of skin lesions, nerves or both, whereas the type 2 reaction presents painful papules or erythematous nodules ${ }^{30}$. Signs of further systemic effects may occur, such as fever, inflammation of the lymph nodes, neuropathy, or alteration of joints, testicles, eyes or other extremities ${ }^{7}$. Reaction episodes tend to take place at distinct points in time (before, during or after a specific HD treatment ${ }^{819}$, or triggered by stress, infection, pregnancy or childbirth ${ }^{3629}$ ) and require immediate clinical intervention.

The treatment is prolonged and sometimes difficult, requiring multiple medications with diverse side effects ${ }^{11}$. Multi-drug therapy (MDT) for leprosy was introduced by the WHO in 1982 and paucibacillary patients are treated with rifampicin and dapsone, while multibacillary patients receive rifampicin, dapsone and clofazimine ${ }^{13}$.

Due to its magnitude as much as its social significance, including the possibility of social stigma and sequelae for the patient and his/her family, leprosy is still one of the most serious public health problems in Brazil ${ }^{12}$.

\section{MATERIAL AND METHODS}

The dermatology department of the University Hospital of Brasília is the referral center for Hansen's disease out-patient 
care and hospitalization related to diagnosis and treatment in the Federal District and surrounding regions.

A retrospective study was carried out using data collected from leprosy patient case files while under treatment from January 1985 to December 2005. Patients were considered eligible for inclusion in the study if their diagnosis was confirmed by clinical evaluation, bacilloscopy and/or biopsy; any patient who had not concluded treatment or was transferred to another health center was excluded.

The demographic and clinical/epidemiological variables analyzed were: gender, race, age of the patient at diagnosis, clinical form of leprosy, bacillary index and reaction episodes. While analyzing the race of the patients, we discovered that only 677 patient charts had completed this information.

In this study, the I, T, BT and TT forms were combined as paucibacillary; similarly, BB, BL and LL were considered multibacillary. Charts that described the patient's clinical form only as borderline were considered multibacillary.

Reactions were characterized as type 1 or 2 and studied for information relating to the frequency, incidence in different clinical forms and correlated with the bacillary index (BI). Despite a study population of 1,124 patients, it was only possible to obtain information on the BI of 900 of them. For this reason, some statistical analyses examined only this group of patients.

In relation to reaction episodes, the diagnostic criteria for type 1 reactions were the appearance of erythema and/or infiltration of previous lesions, appearance of new erythematous or hypochromic lesions, nerve thickening, edema in the hands, feet or face and/or diffuse cutaneous hyperesthesia.

Type 2 reactions were diagnosed in accordance with the presence of the following findings: erythematous nodules (isolated or disseminated), with or without other systemic symptoms, such as fever, asthenia, nerve thickening and pain, myalgia and lymphadenitis.

Some variables (histopathological analysis and therapeutic regimen) collected only during the period from 2000 to 2005 were evaluated separately. In this study, patients were classified according to their treatment as multibacillary when treatment included dapsone, rifampicin and clofazimine or any other alternatives to these drugs, or paucibacillary when treated with rifampicin and dapsone or an alternative regimen.

The data were filed and processed using Microsoft Excel software, 2003 version. Some variables were correlated using the SPSS v.15 software and the Chi-square test was applied with a confidence interval of $95 \%$.

No conflict of interest regarding ethics occurred during the formulation or development of this article.

\section{RESULTS}

Of the 1,124 cases studied, 485 (43.1\%) were women and $639(56.9 \%)$ men. The most prevalent race (color) was mixed (brown), 379 (56\%) patients, followed by European descent (white), 237 (35\%) cases, 60 (8.9\%) were of African descent (black) and 1 (0.2\%) Asian (yellow). In relation to age, $1,036(92.4 \%)$ of the patients were aged more than 15 years-old (Figure 1).

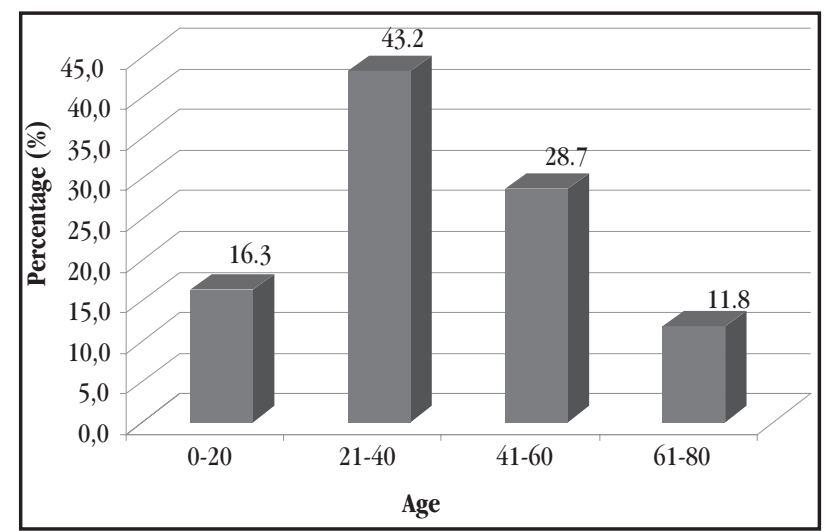

Figure 1 - Distribution of patients according to age group.

The lepromatous clinical form was the most common, determined in 436 (42.9\%) cases, followed by all borderline forms in $312(30.7 \%)$, with a lower prevalence for indeterminate forms in 98 (9.7\%) cases (Figure 2).

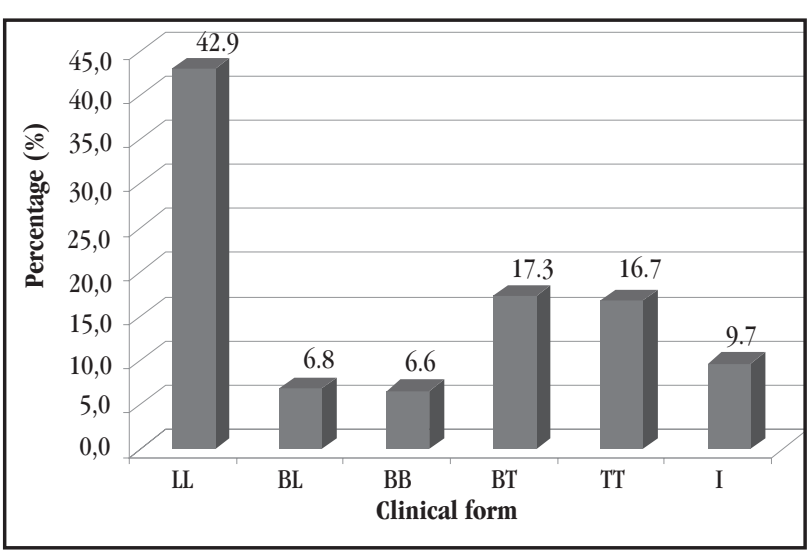

LL: lepromatous, BL: borderline lepromatous, BB: borderline borderline, BT: borderline tuberculoid, TT: tuberculoid, I: indeterminate.

Figure 2 - Distribution of patients according to clinical form.

Episodes of leprosy reaction were witnessed in 328 (29.2\%) patients and type 2 reactions (ENL and multiform erythema) were the most commonly observed, 192 cases, $58.5 \%$ of those who suffered reactions. Reactions were more prevalent in the lepromatous forms, showing a statistically significant difference (Figure 3).

Comparing the occurrence of leprosy reactions in the lepromatous form (LL) with all other clinical forms combined, a positive association occurred between this clinical form and reactions (Table 1 ).

Among the bacilloscopic indices, a predominance of patients with a BI between zero and 0.99 (60\%) was observed (Figure 4).

Evaluation of the patients that presented reaction episodes and correlation of these data with the BI revealed that an increase 


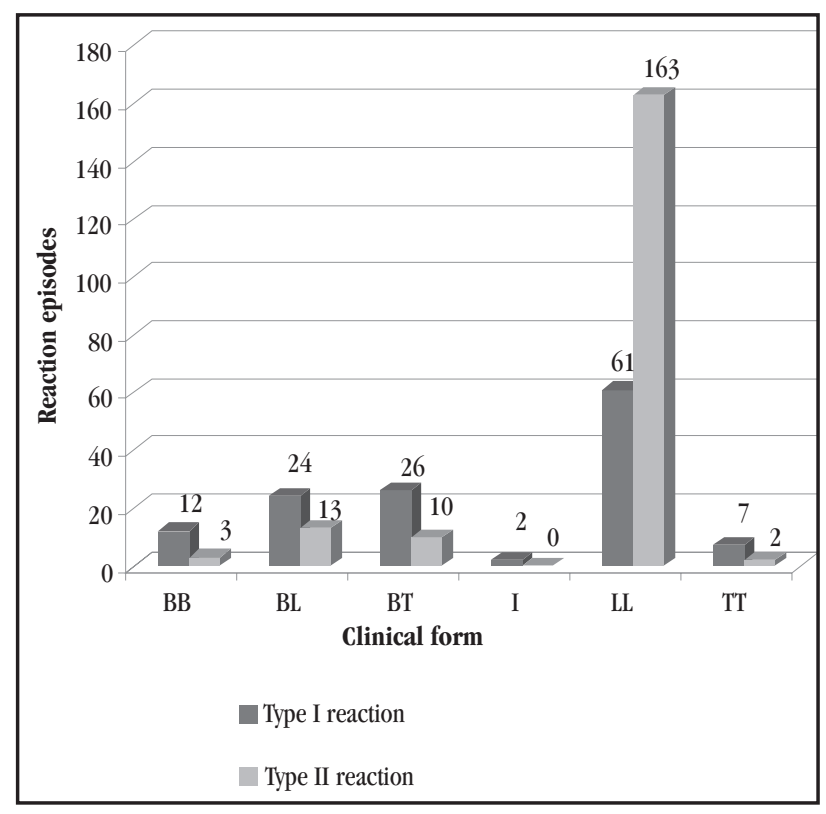

$* \mathrm{p}<0.001$

LL: lepromatous, BL: borderline lepromatous, BB: borderline borderline, BT: borderline tuberculoid, TT: tuberculoid, I: indeterminate.

Figure 3 - Distribution of the number of patients with reaction episodes according to clinical form.

in the BI constitutes a risk factor for the development of leprosy reactions. The occurrence of reaction episodes in patients who presented a higher bacilloscopic index was significantly higher than in those who presented a lower index $(\mathrm{p}<0,001)$.

Table 1 - Number of patients that presented leprosy reactions in the lepromatous form and in all other forms.

\begin{tabular}{lrcr}
\hline & \multicolumn{2}{c}{ Clinical form } & \\
\cline { 2 - 3 } Leprosy reaction & LL & other forms & Total \\
\hline Reaction & 193 & 88 & 281 \\
No reaction & 243 & 492 & 735 \\
\hline Total & 436 & 580 & 1,016 \\
\hline * $\mathrm{p}<0.001$ & & & \\
LL: lepromatous. & & &
\end{tabular}

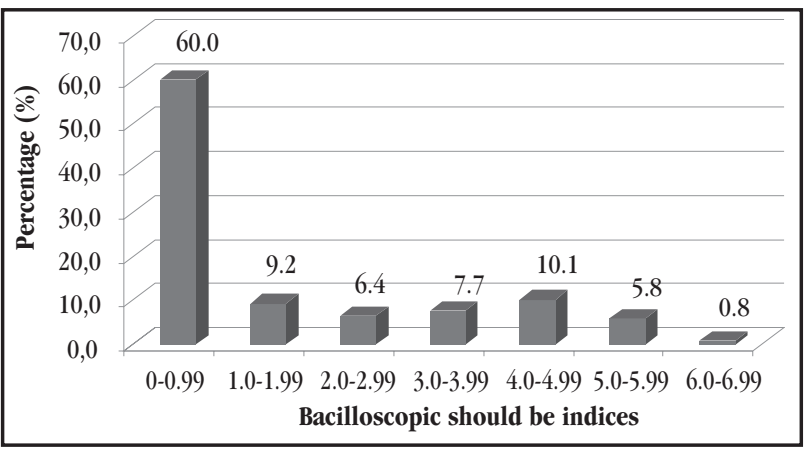

Figure 4 - Distribution of bacilloscopic index values.

The number of patients who suffered reactions was greater in the multibacillary group (240 cases, approximately $36 \%$ of multibacillary patients) in relation to those from the paucibacillary group ( 43 cases, approximately $10 \%$ of paucibacillary patients) (Figure 5). However, in 16 cases, the information regarding

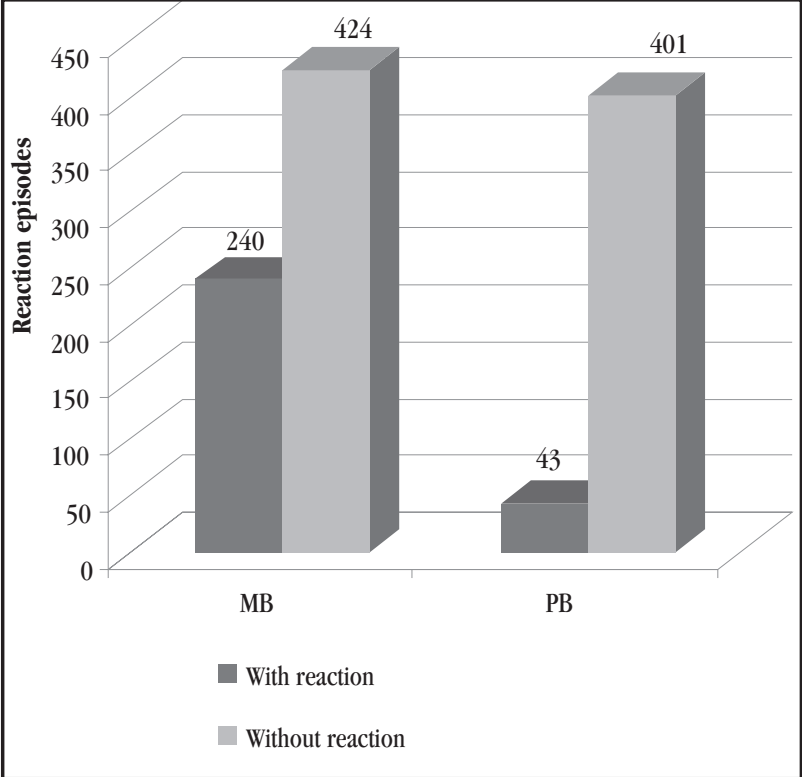

$* \mathrm{p}<0.001$

MB: multibacillary. PB: paucibacillary.

Figure 5 - Distribution of patients that presented leprosy reactions associated with the clinical form of the disease (MB $x$ PB).

leprosy reactions were incomplete and these data were excluded from this analysis.

For some variables, the data were collected only for the period from 2000 to 2005 and are discussed below. It was possible to obtain the results of histopathological analysis for 147 biopsies. An evaluation was realized according to the clinical form and the biopsy and an association was observed between these two variables. The percentages that quantify the cases for which histopathological results coincided with the classification of the clinical form are presented in Table 2.

Table 2 - Evaluation of the correlation between clinical form and bistopathological (biopsy) results.

\begin{tabular}{lc}
\hline Clinical form & Percentage (\%) \\
\hline Lepromatous & 84.2 \\
Borderline lepromatous & 91.7 \\
Borderline borderline & 50.0 \\
Borderline tuberculoid & 96.3 \\
Tuberculoid & 56.0 \\
Indeterminate & 66.7 \\
\hline
\end{tabular}

The patients were also classified as multibacillary (MB) and paucibacillary $(\mathrm{PB})$, according to the type of multi-drug therapy (MDT) that they received. The MB cases corresponded to $78.7 \%$, while the $\mathrm{PB}$ represented $21.3 \%$. In relation to the average duration of each therapeutic regimen, the MB group required an average of 12.8 months and the PB group, 6.6 months. The distribution of the MDT-MB and MDT-PB for each clinical form is represented in Figure 6. 


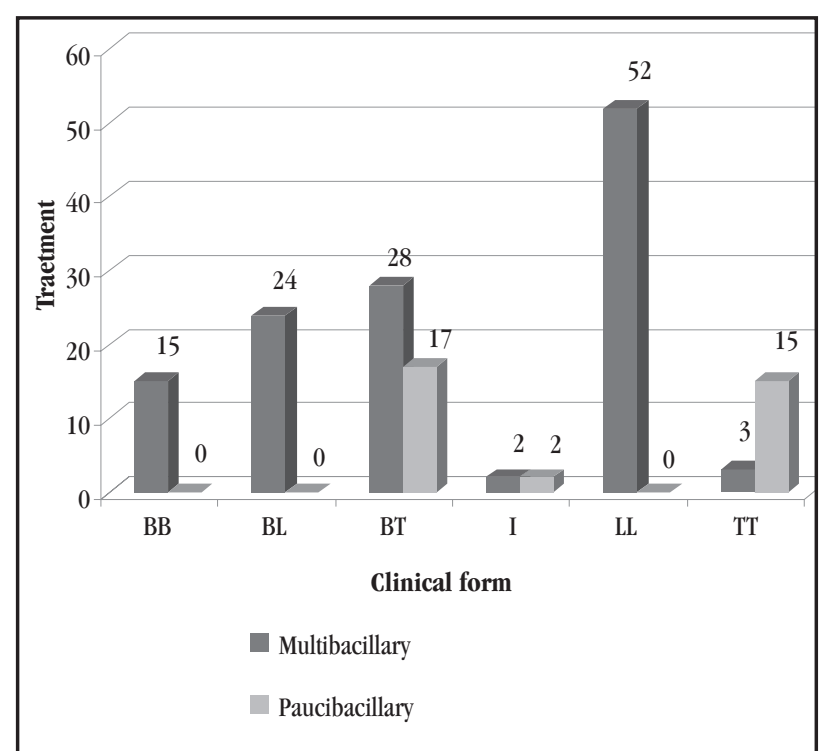

LL: lepromatous, BL: borderline lepromatous, BB: borderline borderline, BT: borderline tuberculoid, TT: tuberculoid, I: indeterminate.

Figure 6 - Distribution of the treatment regimen of each patient for each clinical form.

\section{DISCUSSION}

The incidence of leprosy in the group under study presented similar rates between men and women, regardless of race, with a higher prevalence among those over 15 years of age (92.4\%), which is in agreement with the data in the leprosy literature ${ }^{2424}$. The lepromatous end of the disease spectrum was the most (42.9\%) prevalent, while this finding is not consistent with other studies ${ }^{49}$, it can be explained by the fact that the study occurred in a referral center, which, by nature, receives patients with atypical symptoms, as well as those who are more susceptible to complications, such as the leprosy reactions.

Episodes of leprosy reactions were observed in 328 (58.5\%) patients, with type 2 reactions the most common. The elevated prevalence of reactions reinforces the fact that the Dermatology Department of the University Hospital of Brasilia is a reference for the diagnosis and treatment of leprosy in the Federal District.

A statistically significant association was observed between the occurrence of leprosy reactions and the lepromatous clinical form. This association could be a consequence of the prevalence of lepromatous cases in the present study and the predominance of type 2 reactions, but it is also linked to the immunopathology of the disease, in which multibacillary patients are more susceptible to leprosy reactions due to their bacterial load and higher exposure to antigens. This association has been observed in other studies, such as those undertaken by Cuervas et al, Gomes et al, Kahawita et al and Walker et $\mathrm{al}^{34830}$.

The distribution of the bacilloscopic index in this study showed a greater prevalence of negative bacilloscopic index (BI) or slightly positive $\mathrm{BI}(<1)$. This finding is in contrast with the information that the most commonly observed clinical form in this study was lepromatous, given that this form of the disease is classified as multibacillary. This discrepancy may be the result of the low sensitivity of the examination, errors in some stage of its execution, error in the classification of the clinical form in the patient case file or some other change in the pattern of clinical expression of LL with a low BI. Within the design of this study, these hypotheses could not be further clarified.

In this study, analysis of the results demonstrated that an increase in BI correlates to a statistically significant increase in the number of leprosy reactions $(\mathrm{p}<0.001)$. This information is compatible with the literature that highlights a directly proportional association between the $\mathrm{BI}$ and the development of leprosy reactions, especially ENL ${ }^{6}$. Reactions were also more prevalent in the group classified as multibacillary, which is expected, given that the multibacillary forms are immunologically more unstable and the most common kind of reaction observed was type $2^{36719}$.

With the data collected during the period from 2000 to 2005, analysis of the relation between the clinical form and the histopathological result was undertaken. As described above, an association was observed between these two variables and the analysis confirmed that a significant correlation exists between histopathology and the clinical form, varying from $96.3 \%$ of correlation in the borderline tuberculoid form (BT) to $50 \%$ in the borderline borderline (BB) form.

One possible explanation for the lower percentage of congruity in the $\mathrm{BB}$ clinical form may be the fact that this corresponds to the most unstable form within the spectrum of HD clinical forms. In general, numerous cutaneous lesions with a wide range of types and dimensions are present in the same patient. Maculae, papules and plaques of varying sizes may contain well-defined borders in some areas and diffuse borders in others, revealing the polymorphous aspects of the lesions. The clinical/dermatological variation of this borderline group is also correlated with differing bacteriological, immunological and, above all, histopathological $\operatorname{aspects}^{26}$.

The specific treatment for Hansen's disease is the multi-drug therapy standardized by the WHO. It is administered through a standard regimen in accordance with the operational classification of the patient as either $\mathrm{PB}$ or $\mathrm{MB}^{1531}$.

Therefore, once diagnosed, a Hansen's disease patient must be classified for therapeutic reasons. This classification is paucibacillary (PB) for cases with 5 skin lesions or fewer or multibacillary (MB) in the case of more than 5 lesions ${ }^{15}$.

The patients in the study, included from 2000 to 2005 , were also classified as $\mathrm{MB}$ or $\mathrm{PB}$ according to the operational classification. The $\mathrm{MB}$ patients correspond to $78.7 \%$, while the $\mathrm{PB}$ cases represented $21.3 \%$. A convergence of observations occurred with this study and the literature that states that the $\mathrm{PB}$ regimen is associated with almost all indeterminate and tuberculoid cases, while the MB course is applied to borderline and lepromatous cases $^{24}$.

In relation to the duration of each therapeutic regimen, the $\mathrm{MB}$ group required an average of 12.8 months and the $\mathrm{PB}$ group, 6.6 months. Therefore, it is firmly within the recommended guidelines that stipulates 6 months of supervised doses of rifampicin taken 
over a period of up to 9 months for PB cases (with additional daily doses of $100 \mathrm{mg}$ de sulfone) and 12 months of supervised doses of rifampicin taken over as many as 18 months for $\mathrm{MB}$ cases (with additional daily doses of $100 \mathrm{mg}$ de sulfone and $50 \mathrm{mg}$ of clofazimine, along with a single dose of $300 \mathrm{mg}$ of clofazimine) $)^{15}$.

This study showed the clinical and epidemiological profile of leprosy patients treated over a period of 20 years at the University Hospital of Brasilia, reflecting the characteristics of the disease in the Federal District and surrounding areas, given that this is the regional reference center for the diagnosis and treatment of leprosy. The significant prevalence and frequency of severe complications, such as reactions, emphasize the importance of the ongoing study of leprosy and the need for continued improvement in the scope of knowledge concerning its treatment. Attention is drawn to the fact that it is in the realm of dermatology that the first signs and symptoms of leprosy are often seen; therefore this specialty has a particular level of responsibility in the care given to the patient, as well as in the teaching and research of this disease.

\section{REFERENCES}

1. Alcaïs A, Alter A, Antoni G, Orlova M, Thuc NV, Singh M, Vanderborght PR, Katoch K, Mira MT, Thai VH, Huong NT, Ba NN, Moraes M, Mehra N, Schurr E, Abel L. Stepwise replication identifies a low-producing lymphotoxin- $\alpha$ allele as a major risk factor for early-onset leprosy. Nature Genetics 19:517-522, 2007.

2. Azulay RD, Azulay DR. Micobacterioses. In: Azulay RD, Azulay DR (eds) Dermatologia, $2^{\text {nd }}$ edition, Editora Guanabara Koogan, Rio de Janeiro, p.174-189, 1997.

3. Cuevas J, Rodriguez-Peralto JL, Carrilo R, Contreras F. Erythema nodosum leprosum: reactional leprosy. Seminars in Cutaneous Medicine and Surgery 26:126-130, 2007.

4. Gomes CCD, Gonçalves HS, Pontes MAA, Penna GO. Clinical and epidemiological profile of patients diagnosed with leprosy in a reference center in the northeast of Brazil. Anais Brasileiros de Dermatologia 80:283-288, 2005.

5. Goulart IMB, Penna GO, Cunha G. Immunopathology of leprosy: the complexity of the mechanisms of host immune response to Mycobacterium leprae. Revista da Sociedade Brasileira de Medicina Tropical 35:365-375, 2002.

6. Guerra JG, Penna GO, Castro LCM, Martelli CMT, Stefani MMA. Erythema Nodosum Leprosum: clinical and therapeutic up-date - Part I. Anais Brasileiros de Dermatologia 77:389-407, 2002.

7. Guerra JG, Penna GO, Castro LCM, Martelli CMT, Stefani MMA, Costa MB. Erythema nodosum leprosum case series report: clinical profile, immunological basis and treatment implemented in health services. Revista da Sociedade Brasileira de Medicina Tropical 37:384-390, 2004.

8. Kahawita IP, Lockwood DNJ. Towards understanding the pathology of erythema nodosum leprosum. Transactions of the Royal Society of Tropical Medicine and Hygiene 102:329-337, 2008.

9. Kerr-Pontes LRS, Barreto ML, Evangelista CMN, Rodrigues LC, Heukelbach J, Feldmeier H. Socioeconomic, environmental, and behavioural risk factors for leprosy in North-east Brazil: results of a case-control study. International Journal of Epidemiology 35:994-1000, 2006.

10. Kerr-Pontes LRS, Montenegro ACD, Barreto ML, Werneck GL, Feldmeier H. Inequality and leprosy in Northeast Brazil: an ecological study. International Journal of Epidemiology 33:262-269, 2004.

11. Küstner EC, Cruz MP, Dansis CP, Iglesias HV, Campillo MERR, López JL. Lepromatous leprous: a review and case report. Medicina oral, patología oral y cirugía bucal Medicina Oral, Patología Oral y Cirugía Bucal 11:474-479, 2006.

12. Lapa TM, Albuquerque MFPM, Carvalho MS, Silveira Júnior TC. Análise da demanda de casos de hanseníase aos serviços de saúde através do uso de técnicas de análise espaciall. Cadernos de Saúde Pública 22:2575-2583, 2006.

13. Lockwood DNJ, Suneetha S. Leprosy: too complex a disease for a simple elimination paradigm. Bulletin of the World Health Organization 83:230-235, 2005 .

14. Ministry of Health. Database of the National System of Epidemiological Surveillance - bulletins of weekly notification and SINAN; demographic data from IBGE. Secretariat of Health Surveillance. Available at: http://tabnet.datasus.gov.br/cgi/ idb2006/d09.pdf Accessed on 06/11/2008.

15. Ministry of Health. Guide for the Control of Hansen's Disease. Secretariat of Health Policies, Department of Primary Care, 2002. Available at: http://bvsms.saude.gov. br/bvs/publicacoes/guia_de_hanseniase.pdf Accessed on 06/11/2008.

16. Mira MT, Alcaïs A, Thuc NV, Moraes MO, Di Flumeri C, Thai VH, Phuong MC, Huong NT, Ba NN, Khoa PX, Sarno EN, Alter A, Montpetit A, Moraes ME, Moraes JR, Doré C, Gallant CJ, Lepage P, Vemer A, Vosse E, Hudson TJ, Abel L, Schurr E. Susceptibility to leprosy is associated with PARK2 end PACRG. Nature 427:636-640, 2004.

17. Mira MT, Alcaïs A, Thuc NV, Thai VH, Huong NT, Ba NN, Verner A, Hudson TJ, Abel L, Schurr E. Chromosome 6q25 is linked to susceptibility to leprosy in Vietnamese population. Nature Genetics 33:412-415, 2003.

18. Monot M, Honoré N, Garnier T, Araoz R, Coppée JY, Lacroix C, Sow S, Spencer JS, Truman RW, Williams DL, Gelber R, Virmond M, Flageul B, Cho SN, Ji B, Paniz-Mondolfi A, Convit J, Young S, Fine PE, Rasolofo V, Brennan PJ, Cole ST. On the origin of leprosy. Science 308:1040-1042, 2005.

19. Nery JAC, Duppre NC, Sales AM, Jardim MR, Illarramendi X, Machado AM. Contribution to diagnosis and management of reactional states: a practical approach. Anais Brasileiros de Dermatologia 81:367-375, 2006.

20. Opromolla PA, Dalben I, Cardim, M. Geostatistical analysis of leprosy cases in the State of São Paulo, 1991 - 2002. Revista de Saúde Pública 40:907-913, 2006.

21. Penna GO, Macedo VO, Martelli CMT, Maroja MF, Stefani MMA, Chaul A. Thalidomide in the treatment of erythema nodosum leprosum (ENL): systematic review of clinical trials and prospects of new investigations. Anais Brasileiros de Dermatologia 80:511-522, 2005.

22. Penna MLF, Penna GO. Trend of case detection and leprosy elimination in Brazil. Tropical Medicine and International Health 12:647-650, 2007.

23. Ridley DS, Jopling WH. Classification of leprosy according to immunity: a five-group system. International Journal of Leprosy and Other Mycobacterial Diseases 34:255-273, 1966.

24. Sampaio SAP, Rivitti EA. Hanseníase. In: Sampaio SAP, Rivitti EA (eds) Dermatologia, $2^{a}$ edição, Artes Médicas, São Paulo, p.467-488, 2001.

25. Scollard DM. Leprosy research declines, but most of the basic questions remain unanswered. International Journal of Leprosy 73:25-27, 2005.

26. Souza CS. Hanseníase: formas clínicas e diagnóstico diferencial. In: Symposium Leprosy. Medicina, Ribeirão Preto, julho-setembro 1997. Available at: http://www. fmrp.usp.br/revista/1997/vol30n3/hanseniase_formas_clinicas_diagnostico_ diferencial. pdf Accessed on 06/11/2008.

27. Souza WV, Barcellos CC, Brito, AM, Carvalho MS, Cruz OG, Albuquerque MFM, Alves KR, Lapa TM. Empirical Bayesian model applied to the spatial analysis of leprosy occurrence. Revista de Saúde Pública 35:474-480, 2001.

28. Talhari S, Penna G. Letter to editor - Independent evaluation of GAEL. Leprosy Review 76:180-181, 2005.

29. Ustianowski AP, Lawn SD, Lockwood DN. Interactions between HIV infection and leprosy: a paradox. The Lancet Infectious Diseases 6:350-360, 2006.

30. Walker SL, Lockwood DNJ. The clinical and immunological features of leprosy. British Medical Bulletin 77/78:103-121, 2006.

31. Walker SL, Lockwood DNJ. Leprosy. Clinics in Dermatology 25:165-172, 2007.

32. World Health Organization. Leprosy: global situation. Available at: http://www. who.int/lep/situation/en/Accessed on 06/11/2008 